\title{
The Effect of Microstructure on Replacement Reactions - The Example of Limestone Replacement by Fluorite and Dolomite
}

J. WEBER ${ }^{1,2}$, M.C. CHESHIRE ${ }^{2}$, V.H. DISTEFANO ${ }^{3}$, K.C. LITTRELL $^{2}$. J. ILAVSKY ${ }^{4}$, M. BLEUEL ${ }^{5}$, J.K.BOZELL ${ }^{6}$, A. IEVLEV $^{2}$, A.G.STACK ${ }^{2}$, L.A. ANOVITZ ${ }^{2}$

${ }^{1}$ University of Arizona, USA (julianeweber@email.arizona.edu) 20ak Ridge National Laboratory, USA. ${ }^{3}$ University of Tennessee, USA.

${ }^{4}$ Argonne National Laboratory, USA. ${ }^{5}$ National Institute of Standards and Technology, USA. ${ }^{6}$ University of Nebraska, USA.

Rock microstructure and evolution of pore space controls fluid flow properties in geological formations. During the interaction of fluids and rocks, the mineral phases of which the rock consists can be replaced. While replacement reactions have been studied extensively, the controls of the initial rock microstructure on replacement reactions is not fully understood.

Here, we will discuss two systematic studies, on the replacement of limestone by (1) fluorite and (2) dolomite. Systematically, initial porosities and solubilities were varied as a proxy for microstructure and chemical reactivity, respectively. In batch reactor experiments, limestones were contacted with $\mathrm{NH}_{4} \mathrm{~F}$ or $\mathrm{MgCl}_{2}$ at $120^{\circ} \mathrm{C}$ and $200{ }^{\circ} \mathrm{C}$ respectively for 4 to 317 days. By combining chemical imaging (time-of-flight secondary ion mass spectrometry, ToF-SIMS and scanning electron microscopy with energy dispersive X-ray spectroscopy, SEM-EDX) with (ultra) small angle scattering techniques (X-rays and neutrons), we accessed the multi-scale porosity development over time during the replacement reaction.

In both systems, a higher starting porosity increased the reaction speed, which is the controlling factor over the chemical reactivity in the case of limestone-fluorite replacement (Weber et al., 2019). Furthermore, the replacement of limestone takes place via advantegoeus pathways enhancing the available reactive surface area, e.g. grain and twin boundaries, fractures and interconnected porosity. In the higher porosity limestone, transport along grain boundaries plays a less important role, whereas grain boundaries are an important factor in controlling reaction speed and porosity deveopment in the low porosity limestone. We will discuss the similarities and differences between limestone replacement by flourite and dolomite.

References:

Weber, J. et al. ACS Earth and Space Chemistry 3.9 (2019): 1998-2016. 